\title{
Testing the Conceptual Model of Creativity-Based Teaching Method among High School Students
}

Iranian Evolutionary and Educational Psychology Journal

December 2020: 316-325

(C) University of Hormozgan Publication 2020 DOI: $10.29252 /$ ieepj.2.4.316

http://ieepj.hormozgan.ac.ir

\section{Mohammad Sadegh Hosseini ${ }^{1}$, Nadere Sohrabi ${ }^{* *}$, Hossein Baghooli ${ }^{3}$, Majid Barzegar ${ }^{4}$}

\begin{abstract}
The aim of the present study was testing the conceptual model of creativity-based teaching method among high school students. It was conducted on a sample of experts (including principals, deputies, teachers and counselors) working in 20 public schools in Shiraz (384 people, including 250 males and 134 females) in the academic year of 2019-2020. The method of the present study was a correlational in which researcher-made questionnaires were distributed among the subjects, and then, the fitness of the proposed model and the effect of teaching methods on creative learning were examined using AMOS 24 software. The results of statistical tests showed that students' creativity is influenced by teaching methods.
\end{abstract}

Keywords: Creativity, teaching method, experts, creative learning

\section{Introduction}

Traditional methods, especially lecturing and memorizing and repeating scientific facts have always been considered in the Iranian educational system. It has brought a spirit of passivity for the education system. As a result, natural curiosity has easily given way to passivity and a tendency to imitate others. Caution, instead of questioning and listening, has replaced thinking, while the development of thinking skill has often been considered as the most important function for formal education (Dadgharan \& Etemadmoghaddam, 2016), since an ability in skills is essential to achieve success in the contemporary world, where creation of new knowledge is expanding rapidly. Thus, after graduation, students usually do not have sufficient skills to enter community. Skills such as critical thinking, creativity, public relations, incompatibility analysis and teamwork skills, having a creative, and innovative mind are considered valuable advantage for the growth and flourishment of students' abilities. From a lexical perspective, creativity is the desire for creativity that is potentially present in all people and at all ages and is directly and closely related to the socio-cultural environment. Conditions are required so that this natural desire to be actualized. Fear of deviation and trying to conform to community are barriers of creativity (Dadgharan \& EtemadMoghadam, 2016). Also, from a practical point of view, creativity has existed in human nature since ancient times and has been a part of his or her social behavior (Gholamian Fard, 2013). For this reason, Torrance (1965, quoted by Emami,Jamali \& Isfahani, 2013), argues that creative thinking is an extraordinary force in the education system, since this force in the past donated us alphabet,

1. PhD Student, Department of Psychology, Marvdasht Branch, Islamic Azad University, Marvdasht, Iran

2. Assistant Professor, Department of Psychology, Marvdasht Branch, Islamic Azad University, Marvdasht, Iran

*Corresponding author email: sohrabi_sh2006@yahoo.com

3. Assistant Professor, Department of Psychology, Marvdasht Branch, Islamic Azad University, Marvdasht, Iran

4. Assistant Professor, Department of Psychology, Marvdasht Branch, Islamic Azad University, Marvdasht, Iran 
print, radio, television, a computer, a spacecraft, and will donate other things in the future. Craft and Jeffrey (2001) also argue that creativity should be considered a practical imagination, since it serves human welfare, human progress and development. Saville (2006) also argues that creativity is a state of mind in which multiple intelligences operate in an integrated manner. In such a state, creativity creates a high ability in the person that enables him or her to have a focus for innovation. From a structural perspective, creative thinking and learning is composed of four components, including fluidity, initiative, flexibility and expansion (Yaghoubi \& Bayat, 2011), and the creative process involves constructing, recognizing, defining the problem, preparing and obtaining data related to the problem, giving an idea and evaluation (Malaga \& Ross, quoted by Moshabaki, 1998). The first step in the creative process is preparation. This step involves paying close attention to the problem under investigation to solve the problem. In the second step, referred as latency or development stage (sleep on the problem), the conscious mind's attention shifts away from focusing on the desired problem. The third step is the step of insistence. In this step, creative people are involved with their ideas without considering their consequences and costs. The step of insight is the fourth stage of creativity. In this step, the person finds an idea that he or she has always been looking for but has been unaware of it already. The last step is the investigation step. In this step, new insights or ideas are tested to ensure validity and appropriateness (Moghimi, 2011). However, it should be noted that all people have a natural level of creativity. This ability is affected by biological factors, personality, motivation and education and the environment as a place where creativity is formed is effective on the performance of creativity (Moshabaki, 1998). A creative student is defined as one person who has a searching and creative mind (Quintero, 2015), Thus, to have creative students, it is necessary to design and implement a teaching method appropriate to growth and flourishment of creativity. Teaching method refers to activities that are designed by the teacher with the aim of facilitating learning between the teacher and one or more learners in the form of interaction (Seif, 2011). Since traditional teaching methods (such as lecture) do not provide appropriate mental stimulation for students (Geisslar, 2011), students should be motivated to learn and control by gradually development of awareness of thinking and using creative thinking strategies. Accordingly, students' self-confidence is gradually increased and they become people who think and solve problems independently (Mclivenny, 2013). In fact, to spread creative thinking in a classroom, attention should be paid to teaching methods, students' involvement and interaction in the learning process. Accordingly, students should be actively involved in reading, writing, listening and speaking skills, since this model increases the activity and interest of students in the classroom (Hosseini \& Motavar, 2013). Thus, considering the importance of creativity and creative thinking, the teaching method that helps teachers and students to achieve this goal will be crucial. In other words, given the importance of creativity and creative thinking and its high status among thinkers, it can be stated that any teaching strategy and method resulting in promoting and strengthening creativity and creative thinking is important for education. These goals and methods will not only direct the future of a society towards growth and excellence, but will provide beneficial results for whole society. In this regard, the results of a study conducted by Dehghan Manshadi (2017) showed that the participatory learning method is significantly different from the lecture method in terms of creativity. Thus, schools can improve students' creativity and increase motivation by using the participatory learning teaching method. Also, Hassan, Salibi \& Niusha (2014) concluded that collaborative teaching method increases students' creativity and the results of the components of creativity (fluidity, flexibility, originality) showed the superiority of the cooperative teaching method over traditional teaching method 
in development of creativity in students. Weisi (2017) also showed that teaching based on creative problem solving method has a significant effect on attitudes toward creativity. Kucharcikova and Tokarcikova (2016) found that participatory teaching methods affect the creativity of students significantly. Also, the results of a study conducted by Rahimimand and Abbaspour (2015) showed that students' creativity through discussion and group participation increased more than other methods. Other researchers reported the same result in their research (Such as Ismaeili \& Mousavi, 2015; Poorsalim, Zamani \& Monafi, 2014; Alexander \& Van Wyk, 2012; Servet, 2013; Gholamian Fard, 2013; Arvin, 2012; Jebeli Adeh \& Sobhani, 2012 \& Make, Sonmi \& Muammar, 2008). However, in contrast to the results of other studies, Taherzadeh and Jowkar Kamalabadi (2015) concluded that participatory learning had no significant effect on creativity of students. Given what was stated above, the aim of this study is to evaluate the effect of creativity-based teaching methods on high school students. Thus, the main question is what is the conceptual model of creativity-based teaching method in high school students?

\section{Material and Method}

The present study is applied in terms of objective and correlational in terms of method. The statistical population of the study includes all experts (including head of educational departments in offices, academic advisors and school principals) and specialists in the field of curriculum planning and educational planning in education departments and schools in Shiraz, working in the academic year of 2019-2020. Multi-stage cluster random sampling method was used in this study. Accordingly, from the four districts of Education Department of Shiraz city, two districts were randomly selected. Then, among the schools in each of the selected districts, 20 schools (public and non-profit) were randomly selected. Finally, all experts of the selected schools (including principals, deputies, teachers and counselors) were tested (total participants included 384 people, 250 of which were males and 134 were females, 14 had associate's degree, 170 had bachelor's degree, 130 had master's degree, and 70 had $\mathrm{PhD}$ ). In the present study, participants had a freedom of action to participate in the research. Participants were also ensured that their information and identity will remain confidential.

Instrument:In the present study, to collect and analyze data, a part of the researcher-made questionnaire of creative approaches in the high school curriculum was used. This questionnaire was first developed and standardized by a researcher in 2019. For this purpose, after reviewing previous studies in this area and interviews with a number of experts and academics on the subject of creativity, the initial questionnaire was designed. Then, by implementing this questionnaire on a sample of 90 experts belonged to statistical population of this study, factors that were effective in creativity were extracted by exploratory factor analysis test using SPSS-26 software and classified based on their priority. Based on the results of factor analysis, the factor structure of the questionnaire and the reliability and construct validity of creative approaches were confirmed. This questionnaire assesses six areas of creative approaches in the high school curriculum. These areas include teaching methods, educational content, educators, assessment, physical environment and management). The mentioned questionnaire includes 10 items, scored on a 5-point Likert scale ranging from very low to very high. In the present study, the validity of the questionnaire was confirmed and also the reliability of the questionnaire was obtained at 0.77 using Cronbach's alpha measurement method and 0.72 using splithalf method, indicating good internal consistency between the items of questionnaire. 


\section{Results}

Descriptive results related to teaching method show that its mean variable is 2.67 and its standard deviation is 0.37 . Also, the mean and standard deviation of the subjects' scores in the creativity variable were reported to be 3.18 and 0.37 , respectively.

Table 1. Descriptive results related to the variable of creative approaches

\begin{tabular}{|c|c|c|c|c|}
\hline Variables & Mean & SD & Min. & Max. \\
\hline Creativity & 3.18 & 0.37 & 1.97 & 4.79 \\
\hline Teaching method & 2.67 & 0.72 & 1.20 & 4.60 \\
\hline
\end{tabular}

Before performing the main analysis, the normality of the research variables was examined by Kolmogorov-Smirnov and Shapiro-Wilk tests. Based on the results of Table 2, the distribution of model variables follows the normal distribution. Thus, quantitative statistical analysis on the collected data is allowed.

Table 2. Normality test of the present research variables

\begin{tabular}{|c|c|c|c|c|c|c|}
\hline \multirow{2}{*}{ Variables } & \multicolumn{3}{|c|}{ Kolmogorov-Smirnov } & \multicolumn{3}{c|}{ Shapiro-Wilk } \\
\cline { 2 - 7 } & Statistic & Df & Sig. & Statistic & Df & Sig. \\
\hline Creativity & $0 / 07$ & 382 & 0.06 & 0.97 & 382 & 2.00 \\
\hline Teaching method & 0.05 & 382 & 0.12 & 0.99 & 382 & 2.00 \\
\hline
\end{tabular}

The main question of this research was tested using confirmatory factor analysis process in AMOS 24 software with maximum likelihood method. The analyzed model of the main question of the present research in the form of non-standard coefficients mode and standard coefficients mode is shown in Figures 1 and 2.

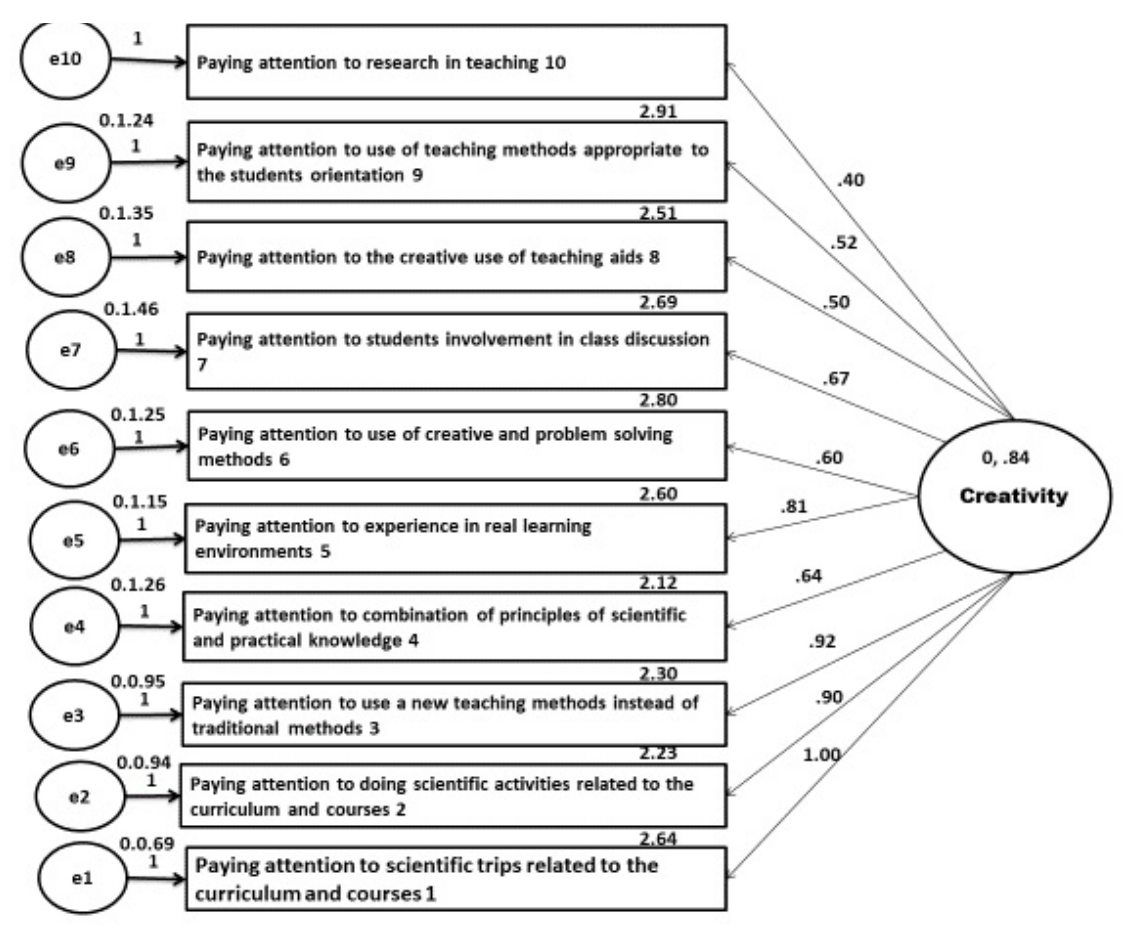

Figure 1. Analyzed model of the main question of the present study in non-standard coefficients mode (B) 


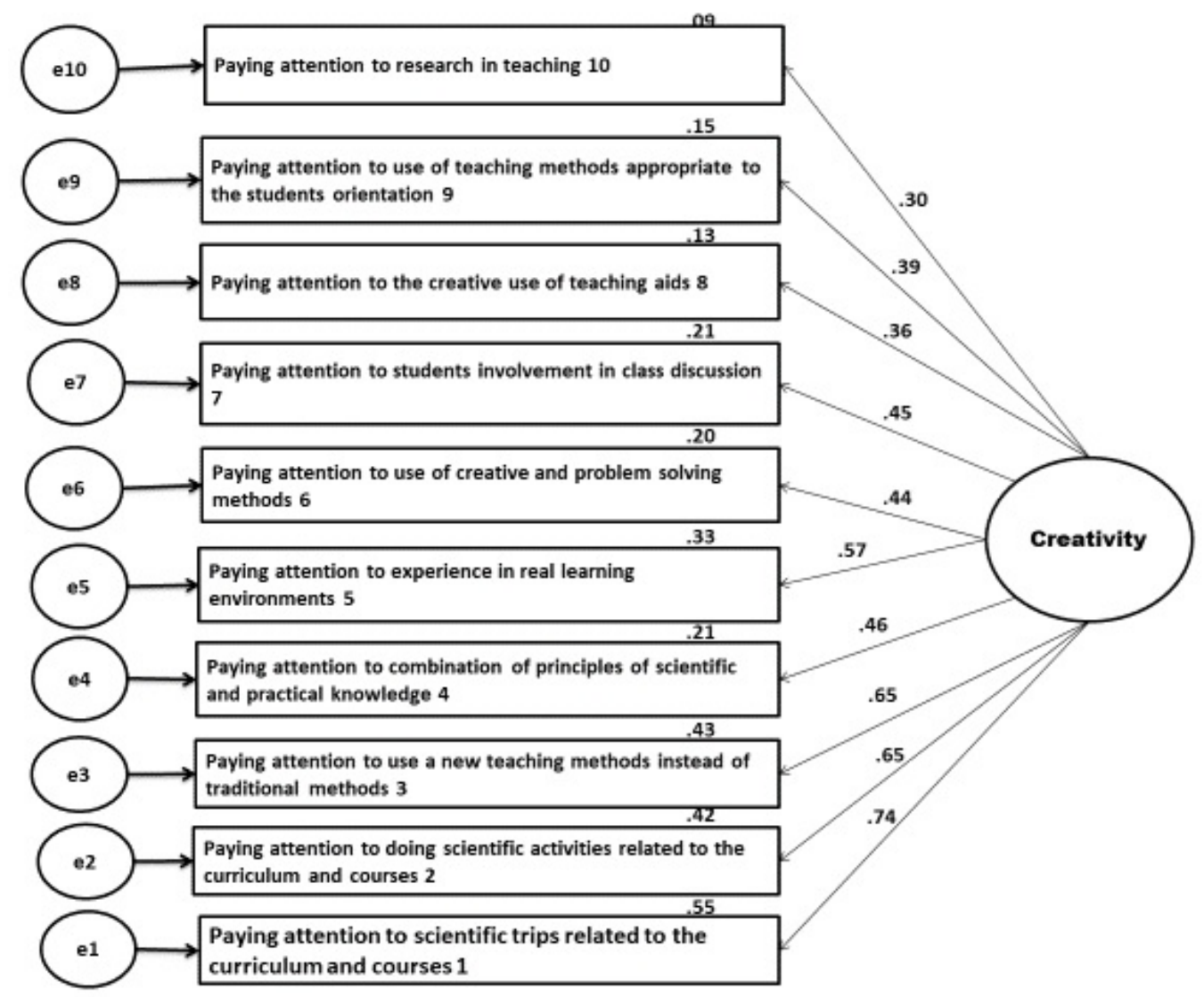

Figure 2. Analyzed model of the main question of the study in standard coefficients mode (beta)

The size of the coefficients observed in the conceptual model of the present study is presented in Table 3.

Table 3. The size of coefficients of the main question of the present study

\begin{tabular}{|l|c|c|c|}
\hline Factors & Standard effect size & Sig. & Priority \\
\hline 1- Paying attention to scientific trips related to the curriculum and courses & 0.14 & 0.01 & 1 \\
\hline 2- Paying attention to doing scientific activities related to the curriculum and courses & 0.65 & 0.01 & 3 \\
\hline 3. Paying attention to use of new teaching methods instead of traditional methods & 0.65 & 0.01 & 2 \\
\hline $\begin{array}{l}\text { 4- Paying attention to the combination of principles of scientific and practical knowl- } \\
\text { edge }\end{array}$ & 0.46 & 0.01 & 5 \\
\hline 5-Paying attention to experience in real learning environments & 0.57 & 0.01 & 4 \\
\hline 6- Paying attention to use of creative and problem solving methods & 0.44 & 0.01 & 5 \\
\hline 7- Paying attention to students' involvement in class discussions & 0.45 & 0.01 & 5 \\
\hline 8. Paying attention to the creative use of teaching aids & 0.30 & 0.01 & 7 \\
\hline $\begin{array}{l}\text { 9- Paying attention to use of teaching methods appropriate to the students' orienta- } \\
\text { tion }\end{array}$ & 0.30 & 0.01 & 6 \\
\hline 10- Paying attention to research in teaching & 0.29 & 0.01 & 8 \\
\hline
\end{tabular}


As shown in Table 3, the reported factor load of item 1 (paying attention to scientific trips related to curriculum and courses) is 0.22 . It means that a unit of increase in item 1 causes $22 \%$ increase in the predicted value for the creativity variable. The reported factor load of item 2 (paying attention to doing scientific activities related to the curriculum and courses) is 0.14 . It means that a unit of increase in item 2 causes $14 \%$ increase in the predicted value for the creativity variable. The reported factor load of item 3 (Paying attention to use of new teaching methods instead of traditional methods) is 0.15 . It means that a unit of increase in item 3 causes $15 \%$ increase in the predicted value for the creativity variable. The reported factor load of item 4 (Paying attention to the combination of principles of scientific and practical knowledge) is 0.07 . It means that a unit of increase in item 4 causes $7 \%$ increase in the predicted value for the creativity variable. The reported factor load of item 5 (Paying attention to experience in real learning environments) is 0.011 . It means that a unit of increase in item 5 causes $11 \%$ increase in the predicted value for the creativity variable. The reported factor load of item 6 (Paying attention to use of creative and problem solving methods) is 0.07 . It means that a unit of increase in item 6 causes $7 \%$ increase in the predicted value for the creativity variable. The reported factor load of item 7 (Paying attention to students' involvement in class discussions) is 0.14 . It means that a unit of increase in item 7 causes $14 \%$ increase in the predicted value for the creativity variable. The reported factor load of item 8 (Paying attention to the creative use of teaching aids) is 0.05 . It means that a unit of increase in item 5 causes $14 \%$ increase in the predicted value for the creativity variable. The reported factor load of item 9 (Paying attention to use of teaching methods appropriate to the students' orientation) is 0.06 . It means that a unit of increase in item 9 causes $6 \%$ increase in the predicted value for the creativity variable. Finally, the reported factor load of item 10 (Paying attention to research in teaching) is 0.04 . It means that a unit of increase in item 10 causes $4 \%$ increase in the predicted value for the creativity variable. Thus, item (1) has the highest importance in the teaching method in increasing the creativity of high school students, followed by items $3,2,5,4,6,7,9,8$ and 10, respectively. Also, the size of the standardized coefficients of the variable dimensions of the teaching method are statistically significant at the level below 0.01 . Therefore, teaching method has an effective role in the creativity of high school students. The fit indices of the analyzed conceptual model of the main research question are presented in Table 4. As shown in Table 4, according to the reported indices, the conceptual model of the main question has an acceptable fitness.

Table 4. Fit indices of the conceptual model of the main question

\begin{tabular}{|c|c|c|c|c|c|c|c|}
\hline Fit indices & DF/ Chi-Square & RMSEA & NFI & TLI & CFI & IFI & RFI \\
\hline $\begin{array}{c}\text { conceptual model of main re- } \\
\text { search }\end{array}$ & 2.32 & 0.05 & 0.88 & 0.91 & 0.93 & 0.93 & 0.85 \\
\hline desired status & $<3$ & $>0.08$ & & & \multicolumn{3}{|c|}{$>0.9$} \\
\hline
\end{tabular}




\section{Discussion}

The present study revealed that teaching method is one of the most important factors influencing creativity. In other words, this result emphasizes the importance of using modern teaching methods to flourish students' creativity. This result is in line with studies reviewed in this study. However, they are not in line with the results of studies conducted by Taherzadeh and Jowkar Kamalabadi (2015), who did not observe the effect of teaching methods on the growth of students' creativity. Thus, selecting an appropriate teaching method to transfer knowledge to students can play a key role in achieving educational goals, since any subject as educational content must be effectively transferred to learners, otherwise, the most useful and practical content will not be transferred to minds of audiences. Based on the results of the present study, to develop a model of teaching methods based on creativity, the most important point is to pay attention to scientific trips related to the curriculum, since presence of students in non-classroom environments and entering nature can stimulate their creativity and curiosity and challenge their mental and physical flexibility to adapt to environmental changes. Also, testing theoretical findings in the real world (even in a laboratory environment) provides an opportunity for students to gain experience and explore the relationships between what they have learned. In addition, being in natural and real environment strengthens a sense of return to creative essence and nature in students, which provides an appropriate condition for flourishment of talents and development of skills and abilities of learners. The second important point in selecting a teaching method is to pay attention to the use of modern teaching methods instead of traditional methods. Many researchers consider traditional teaching methods as one of the major barriers to growth of creativity in education. A number of other researchers also emphasize the point that the traditional system must be transformed and directed towards creative education to have a constructive educational system (Gholamian Fard, 2013). Methods based on creative learning, problem solving, active learning, etc., which challenge students' minds in the learning process and arouse students' curiosity, inquiry, questioning, and critical thinking improve learning and foster creativity in students. In contrast, traditional teaching methods that focus more on lecturing and memorizing theoretical contents do not cause a mental challenge to learners, but cause boredom and lack interest in learning have a devastating effect on the growth of their creative talent. In this regard. Geisslar (2011) argues that traditional classroom methods such as lecture do not provide appropriate mental stimulation for students. The third point is to pay attention to doing scientific activities related to the curriculum. Not sufficing to educational content and going beyond the content of the book is an effective factor in stimulating students' creativity. Educators and parents of students can help students gain a better understanding of what they have learned and the relationships between them by providing scientific content and activities related to the curriculum

and courses. This work, in addition to improving quality, increases the scope of knowledge, its depth and quality. Also, paying attention to experience in real learning environments is the fourth point in adopting a creative teaching method. This teaching method is especially useful for providing courses with practical and workshop nature, since the use of tools and equipment to transform raw materials into final products during the production process stimulates all the physiological senses of students. However, in the classroom setting, only the students' senses of seeing and hearing are activated and sitting at a desk for long periods of time in the classroom environment makes students exhausted and reduces the quality of learning. Activating the five senses in a real learning environment will enhance students' mental arousal and vitality and will develop their creativity. The fifth point is to pay attention to the combination of principles of scientific and practical 
knowledge. It is especially important for creativity in the basic and theoretical sciences, since by knowing the application of what they have in mind as a formula and theory, students can better understand scientific facts and creatively discover and invent new applications for solving everyday problems. Paying attention to the use of creative and problem-solving methods and paying attention to students' involvement in lesson discussions are also points that are as important as the fifth point. In teaching theoretical and formulated contents, the uniformity of the classroom environment and the teacher's voice increases the tediousness of the educational content, and by using creative and problem-solving methods and involving students in class discussions, the spirit of vitality, mobility, activity, and interest of students in purely boring theoretical subject increase, and the boring classroom learning environment becomes a challenging and likable space. In fact, creativity of students is flourished with the change of educational atmosphere and setting. Paying attention to the use of teaching methods in accordance with the students' orientation is the sixth point in selecting a creative teaching method. In other words, many personality, cultural, social, economic, etc. factors play a role in students' tendency to some kind of teaching method, and a new and successful teaching method in one educational setting does not necessarily work in other educational conditions. It reflects the importance of high intelligence of teachers in selecting the teaching method tailored to the educational conditions. By mastering and combining different teaching methods, intelligent teachers can creatively use the method that is more tailored to the educational conditions and learners. Accordingly, in addition to increasing the probability of students' academic success, they can also develop creativity in them. The next important point is to pay attention to the creative use of teaching aids. It refers to means of transmitting knowledge.

Although most teachers use books, pens and notebooks as their teaching tools, smart methods and the use of various teaching and learning aids in schools have provided appropriate conditions for diversifying selection of teaching and learning aids. If these diverse tools are used correctly and in the right place, learners will learn the educational content faster and deeper, they will be less tired and they will have more opportunities to think about what they have learned and discover the relationships between them, resulting in creativity and innovation. In fact, to achieve creativity, the speed of reading should be increased. In fact, teaching methods should be reformed to create long-term and creative learning. In this regard, the principles of organizing content and activating the brain using mnemonic methods should be used (Salehi Taleghani, 2007). The last point in this regard is paying attention to research in teaching. This point is associated with other dimensions mentioned above in several ways. In fact, the goal of research in teaching is to stimulate curiosity and inquiry and questioning and achieve answers using scientific methods. It means that students should be motivated to test their knowledge in an environment outside the classroom and discover new dimensions. Curious students in their leisure time seek to test classroom content in the real and virtual world and are not justified by any superficial or unscientific answers. Hence, they break the boundaries of old structures and creatively create new scientific horizons. Therefore, teachers and educators are recommended to change their teaching methods in accordance with the latest scientific achievements to develop creativity in students and to avoid relying merely on traditional teaching and lecture-based methods. 
Declaration of Conflicting Interests: The author(s) declared no potential conflicts of interest with respect to the

research, authorship, and/or publication of this article.

Funding: The authors received no financial support for the research, authorship, and/or publication of this article.

Acknowledgements: We are grateful to all the participants who have contributed to this study.

\section{References}

Alexander, G., \& Van Wyk, M. (2012). Exploring the Value of Cooperative Learning in Enhancing Teaching in Integrated School Environments of the Northern Cape Province. Journal of Procedia Social and Behavioral Science, 47, 1945-1949.

Arvin, F. (2012). Comparison and investigation of the effect of participatory learning and lecture-based methods on creative thinking and academic achievement of third grade middle school female students in Yazd. Master's Thesis, Faculty of Humanities, Yazd University.

Craft, A., \& Jeffrey, R. (2001). The universalization of creativity. In A. Craft, R. Jeffrey, \& M. Leibling (Eds.). Creativity in education (pp. 1-13). London: Continuum.

Dadgran, M., \& Etemadmoghaddam, M. (2016). Identify the core competencies of creativity and managers of private newspapers. Journal of Innovation and Creativity in Human Science, 6(1), 175-196.

Dehghan Menshadi, F. (2017). A comparative study on the participatory learning and lecture-based teaching methods on creativity and entrepreneurial spirit of female high school students in District 1 of Yazd. Master Thesis in education and improvement of human resources, Imam Javad Institute of Higher Education.

Emami, M., Jamali, E., \& Esfahani, M.J. (2013). Investigating the Relationship between Organizational Trust and Organizational Creativity, Quarterly Journal of Initiative and Creativity in Humanities, 5, (3), 33-34.

Geisslar, G. (2011). Improving Students' Critical Thinking, Creativity, and Communication Skills. Journal of Instructional Pedagogies 8.

Gholamian Fard, A. (2013). Investigating the effect of guided exploratory learning method on strengthening the creative thinking of sixth grade elementary school girls in Qom. Master's Thesis in Curriculum Planning, Faculty of Psychology and Social Sciences, Department of Educational Sciences, Islamic Azad University, Central Tehran Branch.

Hassani, F., Salibi, j., \& Beheshteh, N. (2014). The effectiveness of the combined teaching of critical thinking and creative thinking on self-directed learning of secondary school students in Qom. Journal of Scientific, Innovation and Creativity Research in Humanities, 4, (3), 55-75.

Hosseini, S.M.H, \& Motavar, M. (2013). Designing, compiling and validating a collaborative learning guide model for the "Read and Write Persian" curriculum for elementary school, Educational Innovations Quarterly, 46, 10-50.

Ismaeili, E., \& Mousavi, F. (2015). Comparison between the participatory teaching method through e-learning environment and lecture-based e-learning on creativity and academic achievement of students, Third National Conference on Sustainable Development in Educational Sciences and Psychology, Social and Cultural Studies, August 2015, Tehran, Iran 
Jebeli Adeh, P., \& Sobhani, A. (2012). The effect of using creative teaching methods on the creativity of fourth grade elementary students in Golestan province. Journal of Creativity and Innovation in Humanities, 2, 135-144.

Kucharcikova, A., Tokarcikova, E. (2016). Use of participatory methods in teaching at the university, The Online Journal of Science and Technology, pp. 82-90.

Make, J., Sonmi, J., \& Muammar, O. (2008). Development of creativity: the influence of varying levels of implemation of the DISCOVER curriculum model, a non-traditional pedagogical approach, 18, 402- 417.

McIlvenny, L. (2013). Critical and creative thinking in the new Australian curriculum part one. Access, 27, (1) $18-22$.

Moghimi, S.M.(2011).Organization and management of a research approach. Tehran: Termeh Publications.

Moshabaki, A. (1998). A new look at the concept of work conscience in improving the level of productivity of the organization.Journal of Future Studies Management,9(1), 131-143.

Poorsalim, A., Zamani, E., \& Manafi Sharafabad, K. (2014). The effect of participatory learning on the creative thinking offifth grade male students in Koohdasht city in the course of experimental sciences. Journal of Thought and Child, Institute of Humanities and Cultural Studies, 5( 1), 59-63.

Quintero, M. (2015). Innovation for Media: Tools and Strategies for Delivering Successful Content. Florida: J. Ross Publishing.

Rahimimand, M., \& Abbaspour, A. (2015).The effect of new teaching methods on students' creativity and academic achievement. Journal of Innovation and Creativity in the Humanities, 4, (4), 4-9.

Salehi Taleghani, F. (2007). How to eliminate boredom of personnel in safety trainings? Bimonthly Quarterly Journal, 47, 26-27.

Saville, D. (2006). Emotional Intelligence in Policing. Police Chief Magazine; 13 (74): 166-181.

Seif, A.A. (2012). Modern Educational Psychology. (Fiftieth Edition). Tehran: Doran Publications.

Servet, C. (2013). Implementing cooperative learning in the lnnguage classroom: opinions of turkish teachers of English. Journal of procedia Social and Behavioral Science, 70, 1852-1859.

Taherzadeh, S., \& Jowkar Kamalabadi, A. (2015). The Effect of Collaborative Learning on Academic Achievement and Creativity Growth of Secondary School Students, Second National Conference on Sustainable Development in Educational Sciences and Psychology, Social and Cultural Studies, Tehran, Soroush Hekmat Mortazavi Center for Islamic Studies and Research, Mehr Arvand Institute of Higher Education, Center of strategies for achieving sustainable development.

Weisi, M. (2017). The Effectiveness of Creative Problem Solving Teaching Method on Attitudes Towards Creativity and Learning the Experimental Sciences of Sixth Grade Students in Kermanshah. Master Thesis, Payam-e Noor University, center of Kermanshah.

Yaghoubi, A., \& Bayat, A. (2011). The relationship between students' self-esteem of Bu Ali Sina University and their happiness and creativity. Journal of Innovation and Creativity in the Humanities, 3, 57-61. 